\title{
Berberine Synergy with Amphotericin B against Disseminated Candidiasis in Mice
}

\author{
Yongmoon HAN* and Jue-Hee LeE \\ College of Pharmacy, Dongduk Women's University; Seoul, 136-714, Korea. \\ Received November 8, 2004; accepted December 15, 2004
}

\begin{abstract}
In present study, we investigated the synergic effect of berberine against disseminated candidiasis caused by the pathogenic fungus, Candida albicans. Berberine inhibited the growth of $C$. albicans under in-vitro condition. The broth susceptibility revealed the synergic effect of berberine with amphotericin B (Amp B). To confirm these results under the in-vivo condition, the effect was examined in mice against disseminated candidiasis. Results showed mice that were given diluent (negative control), Amp B $(0.5 \mathrm{mg} / \mathrm{kg}$ of body weight), or berberine $(1 \mathrm{mg} / \mathrm{kg}$ of body weight) had mean survival times (MST) of approximately 12,14 , and $17 \mathrm{~d}$, respectively. On the contrary, mice that were treated using a combination of the two agents at the same concentrations resulted in a MST value of $36 \mathrm{~d}$, surviving at an average of $22 \mathrm{~d}$ longer than the mice group treated only with the Amp B. This MST value was almost same as MST value from the mice that were given four times the Amp B dose. These data indicate that the combination of Amp B and berberine could reduce approximately $75 \%$ of the Amp B dose, implying that berberine indeed has synergy with Amp B against the disseminated disease.
\end{abstract}

Key words Candida albicans; amphotericin B; berberine; synergic effect; mice

Candida albicans is the most common cause of opportunistic fungal disease in humans. ${ }^{1)}$ In fact, this fungus is also known as the fourth leading cause of nosocomial infections. ${ }^{2,3)}$ Over the past few decades, increasing incidence of candidiasis due to this fungus parallels the growing numbers of immmunocompromised people. ${ }^{2-5)}$ In immunocompromised people, disseminated candidiasis is sometimes a serious disease which often results in death. ${ }^{6}$ In addition to the disseminated disease, C. albicans also causes local infections such as vaginitis and thrush. In case of vulvovaginal candidiasis, C. albicans is the most common etiological agent. ${ }^{7,8)}$ The treatment for the candidiasis includes antifungal drugs, mainly amphotericin B (Amp B) and the azoles. Furthermore, Amp B has been considered as the drug of choice for the treatment of fungal infections. ${ }^{9,10)}$ However, due to its poor permeability across the membrane, ${ }^{11)}$ an increased amount of Amp B must be administered to patients in clinical situations, thus often resulting in severe side effects such as renal damage. ${ }^{12,13)}$ To lessen the severity of the side effects, Amp B is often combined with other antifungal drugs such as the azole ${ }^{14-16)}$ but data reporting resistance of $C$. albicans to the azole have been recently increasing. ${ }^{17-19)}$ Thus investigation of reducing the Amp B dose by combining it with a new antifungal product appears to be important.

As a part of the investigation, we tested a possibility of combination therapy with an alkaloid berberine that has quaternary nitrogen, polycyclic and planar structure. ${ }^{20)}$ The plants that produce berberine is well protected against microorganisms due to the allelochemical activities of berberine, and thus, it appears likely that the berberine functions as a chemical defence compound. ${ }^{20)}$ Berberine can be assumed to be quite safe considering that the lethal dose of berberine is known to be approximately $23 \mathrm{mg} / \mathrm{kg}$ of body weight in mice. ${ }^{21)}$ According to the previous reports of others berberine is shown to have both antifungal ${ }^{2-24)}$ and antibacterial effects ${ }^{25,26)}$ under the in vitro condition. We also reported that berberine had antifungal effect on the growth of $C$. albicans as determined by agar diffusion method. ${ }^{27)}$ Continuing the study of antifungal activity of berberine, we investigated if berberine had a synergic effect with Amp B against disseminated candidiasis caused by C. albicans in animal models.

\section{MATERIALS AND METHODS}

Organisms and Culture Conditions C. albicans strains CA-1 and A-9, characterized previously, ${ }^{28-31)}$ were each grown in glucose-yeast extract-peptone (GYEP) broth at $37^{\circ} \mathrm{C}$. Yeast cells collected from the broth cultures were washed with sterile cold Dulbecco's phosphate-buffered saline (DPBS; Sigma, St. Louis, U.S.A.) solution and enumerated by hemocytometer to obtain desired numbers of yeast cells.

Mice BALB/c female mice (Charles River Labs, U.S.A.) were used at 6 to 7 weeks of age. The mice were maintained in the animal facility at Dongduk Women's University.

Berberine The berberine was purchased from Sigma and confirmed by $\mathrm{HCl}-\mathrm{H}_{2} \mathrm{O}_{2}$ color test and thin layer chromatography (TLC). In the TLC analysis, a mixture of methanol and chloroform at a ratio of 1 to 5 by volume was used as a developing solvent.

Determination of the Berberine on the $C$. albicans Strains Effect of the berberine on the growth of C. albicans yeast cells was examined by agar diffusion susceptibility test as described previously. ${ }^{27)}$ In brief, viable $C$. albicans yeast cells $\left(5 \times 10^{5}\right.$ yeast cells per $\left.\mathrm{ml}\right)$ suspended in sterile DPBS were inoculated with a sterile swab on a GYEP agar plate. Wells $(6 \mathrm{~mm}$ in diameter) were dug out using a metallic puncher on the GYEP agar plate. The berberine was dissolved in sterile DPBS; syringe-filtered $(0.45 \mu \mathrm{m}$; Sartorius AG, Göttingen, Germany); and diluted in DPBS at concentration of 50,100 , and $200 \mu \mathrm{g} / \mathrm{ml}$, respectively. One hundred microliters of the each dilution was put into a designated well on the plate. A control well received the same volume of only diluent (DPBS), instead of the berberine dilution. The plate was incubated at $37^{\circ} \mathrm{C}$. After the 48 -h incubation, sizes of growth-inhibited zones were measured. In case of the Amp B (Gibco/BRL, Grand Island, N.Y., U.S.A.), the antifungal drug was tested at 5,10 , and $20 \mu \mathrm{g} / \mathrm{ml}$, respectively, by the same 
method as described above.

A synergic effect of the berberine was first examined by the broth susceptibility test as follows; to viable $C$. albicans yeast cells in GYEP broth (a final concentration of $5 \times 10^{5}$ cells per $\mathrm{ml}$ ) contained in sterile plastic microcentrifuge tubes (Blue $\mathrm{Max}^{\mathrm{TM}}$, Becton Dickinson Labware, Franklin Lake, NJ. U.S.A.), $0.1,0.5$, or $1 \mu \mathrm{g} / \mathrm{ml}$ of Amp B, respectively, was put. Simultaneously, in one set of this preparation, a fixed amount $(50 \mu \mathrm{g} / \mathrm{ml})$ of the berberine was added to each of those tubes. In another set, sterile DPBS of equal volume was added instead of the berberine preparation as control backgrounds. A total volume of the cultures was $1 \mathrm{ml}$ for the both sets. All of the tubes were incubated at $37^{\circ} \mathrm{C}$ on a shaker incubator (150 rpm; N-Biotec, Seoul, Korea) for $48 \mathrm{~h}$. After the incubation, respective cultures from the tubes were serially diluted in sterile DPBS, and $100 \mu \mathrm{l}$ of the diluted culture was inoculated to the surface of a fresh GYEP agar plate by applying the spreading method for the enumeration of colony forming units (CFU).

Animal Studies Based on the in-vitro data, the synergic effect was determined in animal model. Twenty mice were grouped into four subgroups. Each group was given, peritoneally (i.p.), a mixture of the berberine and Amp B, the berberine, Amp B, or diluent (DPBS), respectively. One hour later, the animals were infected intravenously (i.v.) with a volume of $0.2 \mathrm{ml}$ of live $C$. albicans yeast cells $\left(25 \times 10^{5}\right.$ cells $\left./ \mathrm{ml}\right)$, and their survival rates were measured as described previously. ${ }^{28,29,31)}$ Concentrations of the berberine and Amp B were at 1 and $0.5 \mathrm{mg} / \mathrm{kg}$ of body weight, respectively. These experiments were repeated three times. The berberine dose selected in this study resulted in a marginal protective effect against disseminated candidiasis in the murine model we have defined in our previous work (our unpublished data).

Prior to these experiments, Amp B was tested at various doses such as $0.5,1$ and $2 \mathrm{mg} / \mathrm{kg}$ of body weight, respectively, against the disseminated disease. Control mice received only DPBS by the same i.p. route before an i.v.-challenge with the yeast cells.

Statistics Statistical significance of differences in survival times was calculated through the Kaplan-Meier method (New Statistic for Windows; SPSS, Chicago, U.S.A.). For all other analyses, Student's $t$ test was used.

\section{RESULTS AND DISCUSSION}

The berberine displayed the color-change from yellow to reddish purple color, as determined by the $\mathrm{HCl}-\mathrm{H}_{2} \mathrm{O}_{2}$ color test. The TLC analysis resulted in a single spot confirming the purity of the berberine (data not shown). To determine if the berberine had an anticandidal activity, agar diffusion susceptibility test was done. Results from the susceptibility tests showed that the berberine inhibited growth of the yeast cells that surrounded wells containing the berberine (Table 1). This anticandidal activity was in a dose-dependent manner, which was less effective when compared to anticandidal activity resulted from Amp B (Table 1). The berberine resulted in almost same growth-inhibitory effect on the respective strains of the C. albicans.

For determination of a synergic effect, anticandidal activities of the combinations of a fixed amount of the berberine
Table 1. Anticandidal Effect of the Berberine (A) and Amphotericin (B) on Candida albicans Determined by Agar Diffusion Susceptibility Method (A)

1. C. albicans $\mathrm{CA}-1$

\begin{tabular}{cccc}
\hline \hline \multicolumn{4}{c}{ Conc. of the berberine $(\mu \mathrm{g} / \mathrm{ml})$} \\
\hline None & 50 & 100 & 200 \\
\hline \multicolumn{4}{c}{ Size of inhibitory zone ${ }^{a)}(\mathrm{mm})$} \\
\hline $6^{b)}$ & 7 & 12 & 24 \\
\hline
\end{tabular}

2. C. albicans A-9

\begin{tabular}{cccc}
\hline \hline \multicolumn{4}{c}{ Conc. of the berberine $(\mu \mathrm{g} / \mathrm{ml})$} \\
\hline None & 50 & 100 & 200 \\
\hline \multicolumn{4}{c}{ Size of inhibitory zone $(\mathrm{mm})$} \\
\hline 6 & 8 & 16 & 27 \\
\hline
\end{tabular}

(B)

\begin{tabular}{cccc}
\hline \hline \multicolumn{4}{c}{ Conc. of amphotericin B $(\mu \mathrm{g})$} \\
\hline None & 5 & 10 & 20 \\
\hline \multicolumn{4}{c}{ Size of inhibitory zone $(\mathrm{mm})$} \\
\hline 6 & 6 & 14 & 25 \\
\hline
\end{tabular}

a) The size includes diameter of the well. b) The 6 indicates size of well in diame-

Table 2. Synergic Effect of Amphotericin B Combined with the Berberine (A) Amphotericin B in absence of the berberine

\begin{tabular}{ccc}
\hline \hline $\begin{array}{c}\text { Conc. of } \\
\text { amphotericin B }(\mu \mathrm{g} / \mathrm{ml})\end{array}$ & Berberine & CFU/ml \\
\hline None & None & $(1.21 \pm 12)^{a)} \times 10^{8}$ \\
0.1 & None & $(1.12 \pm 21) \times 10^{8}$ \\
0.5 & None & $(8.0 \pm 18) \times 10^{4}$ \\
1.0 & None & $(1.6 \pm 25) \times 10^{2}$ \\
\hline
\end{tabular}

(B) Amphotericin B in presence of the berberine

\begin{tabular}{ccc}
\hline \hline $\begin{array}{c}\text { Conc. of } \\
\text { amphotericin B }(\mu \mathrm{g} / \mathrm{ml})\end{array}$ & $\begin{array}{c}\text { Berberine } \\
(\mu \mathrm{g} / \mathrm{ml})\end{array}$ & CFU/ml \\
\hline None & 50 & $(3.9 \pm 3.5) \times 10^{7}$ \\
0.1 & 50 & $(3.1 \pm 6.3) \times 10^{7}$ \\
0.5 & 50 & $(1.1 \pm 3.6) \times 10^{4}$ \\
1.0 & 50 & $(1.2 \pm 2.7) \times 10$ \\
\hline
\end{tabular}

a) Mean \pm S.E.

and various concentrations of amphotericin B were determined. Results showed that the culture treated with the berberine alone had $3.9 \times 10^{7} \mathrm{CFU} / \mathrm{ml}$, resulting in CFU reduction up to approximately $66 \%$ as compared to $\mathrm{CFU}$ value of the control culture $\left(1.21 \times 10^{8} \mathrm{CFU} / \mathrm{ml}\right)$ that received neither Amp B nor the berberine (Table 2). The combination of the berberine and amphotericin $\mathrm{B}$ at $0.5 \mu \mathrm{g} / \mathrm{ml}$ resulted in $1.1 \times 10^{4} \mathrm{CFU} / \mathrm{ml}$, whereas the same concentration of Amp B without the berberine resulted in $8.0 \times 10^{4} \mathrm{CFU} / \mathrm{ml}$. When the dose of Amp B was doubled in the combination, there was 

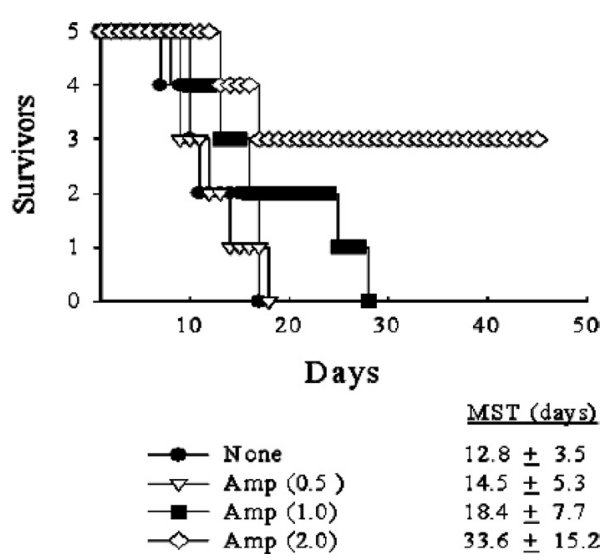

$12.8 \pm 3.5$

$14.5 \pm 5.3$

$18.4+7.7$

$33.6 \pm 15.2$

Fig. 1. Dose-Dependent Effect of Amphotericin B against Disseminated Candidiasis

Mice that received amphotericin B (Amp B), i.p. at various doses were infected with C. albicans yeast cells by an i.v.-route, and their survival times were measured. The Amp B at 0.5 or $1 \mathrm{mg} / \mathrm{kg}$ of body weight resulted in no protection of mice, whereas Amp B at $2 \mathrm{mg} / \mathrm{kg}$ of body weight was protective when these results were compared to the survival time of untreated (control) mice $(p<0.05)$. MST stands for mean survival time.

more than $92 \%$ of $\mathrm{CFU}$ reduction.

The mice that received $0.5 \mathrm{mg} / \mathrm{kg}$ Amp B of body weight and those that received DPBS had a mean \pm S.E. of $14.5( \pm 3.5)$ and $12.8( \pm 3.5) \mathrm{d}$, respectively, thus resulting in almost similar rates of survival times (Fig. 1). At the doubled dose of Amp B, there was a slight increase of the survivability in mice as compared to survival time from the DPBS-received (control) mice. However, the difference was statistically insignificant. In contrast, three out of five mice given $2 \mathrm{mg} / \mathrm{kg}$ Amp B of body weight survived until the end of 46d observation (Fig. 1). Based on these data from three repeated experiments, we chose the dose of $0.5 \mathrm{mg} / \mathrm{kg} \mathrm{Amp} \mathrm{B}$ as a minimal dose for determining the synergic effect by the berberine.

For studies of the synergic effect on disseminated candidiasis, we gave mice the combination of the berberine and Amp B before the i.v.-challenge with yeast cells. Animals that were given DPBS (negative control), Amp B, the berberine, or Amp B and the berberine resulted in a mean \pm S.E. of $12.2( \pm 3.0), 14.4( \pm 2.3), 17.2( \pm 5.7)$, and $(35.6 \pm 12.8) \mathrm{d}$, respectively (Fig. 2). When the survival times from the mice given the combination were compared with survival times from DPBS-received mice, the differences between the two groups were statistically significant $(p<0.005)$. As before, mice given Amp B $(0.5 \mathrm{mg} / \mathrm{kg}$ of body weight $)$ had similar survival days as the DPBS-given control mice. Mice administered the berberine alone survived slightly longer than the control mice groups although this result was not statistically significant. However, the mice treated with the combination survived $23 \mathrm{~d}$ longer than the control mice during the period of the $46 \mathrm{~d}$-observation (Fig. 2). Mice that received a double dose of Amp B (1 mg/kg of body weight) without the berberine survived longer, but their survival rate was still less than the combination therapy-treated mice group (Figs. 1, 2). Mice given four times the Amp dosage had a similar survival time as the mice given the combination therapy. Each of repeated experiments showed similar results.

This work documents discovery of a natural product, berberine, that shows synergy with Amp B. Our data demon-

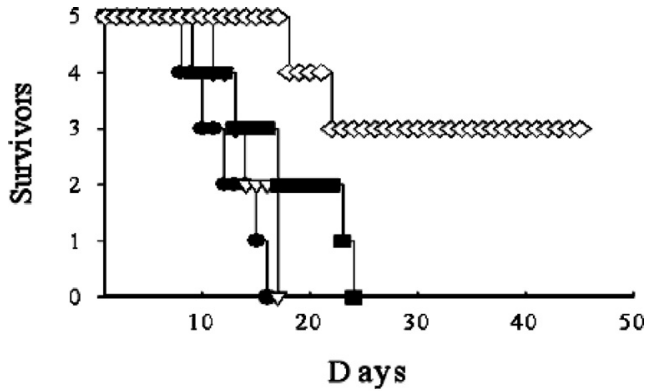

MST (days)

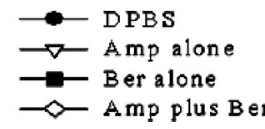

$12.2 \pm 3.0$

$14.4 \pm 2.3$

$17.2+5.7$

$35.6 \pm 12.8$

Fig. 2. Synergy of Berberine with Amphotericin B to Disseminated Candidiasis

Mice were given Amp B $(0.5 \mathrm{mg} / \mathrm{kg})$, berberine $(1 \mathrm{mg} / \mathrm{kg})$, or a combination of berberine $(1 \mathrm{mg} / \mathrm{kg})$ and amphotericin B (Amp B; $0.5 \mathrm{mg} / \mathrm{kg})$, respectively, before the i.v.-challenge with the yeast cells, and their survival times were measured. When the survival rates of mice given the combination were compared to survival rates from mice that received DPBS, the differences were statistically significant $(p<0.005)$. Mice given either Amp B or the berberine had similar survival days as the untreated (DPBS) mice. The mice treated with the combination survived around $23 \mathrm{~d}$ longer than the DPBS-received mice during the period of $46 \mathrm{~d}$-observation $(p<0.05)$. This indicates the berberine had synergy with Amp B. Ber stands for berberine, respectively. MST stands for mean survival time.

strated that berberine inhibited the growth of $C$. albicans yeast cells as determined by both agar diffusion and broth susceptibility-tests. Although the anticandidal activity of berberine alone was not as efficient as Amp B, a combination of Amp B with berberine strikingly enhanced killing of the yeast cells. In animal experiments, mice that were given a combination of minimal doses of berberine and Amp B, respectively, before an i.v.-challenge with $C$. albicans yeast cells were protected against the disseminated disease at a strikingly high rate of survivability. The survival rates were much greater than survival rates resulted from mice treated with four folds the Amp B dose. The dose of Amp B resulted in almost no protection of the mice to the disseminated disease when administered alone without the berberine. These data indicate that the protection is mediated by berberine synergy with Amp B. By analyzing these data, more than $75 \%$ of the clinical dose of Amp B can be reduced if Amp B is combined with berberine for the fungal treatment. In addition, considering the lethal dose of berberine is about $23 \mathrm{mg} / \mathrm{kg}$ in mice, ${ }^{21)}$ it is assumed that the anticandidal effect may be increased in the combination therapy regimen by increasing the concentration of berberine.

In conclusion, we show that berberine has a synergistic effect against disseminated candidiasis. This observation is the first report showing the evidence of in-vivo synergic effect of berberine with Amp B.

\section{REFERENCES}

1) Schaberg D. R., Culver D. H., Gayner R. P., Am. J. Med., 16, 72S75S (1991).

2) Body G. P., J. Hosp. Infect., 11 (Suppl. A), $411-426$ (1988).

3) Edwards J. E., N. Engl. J. Med., 324, 1060-1072 (1991).

4) Fisher-Hoch S. P., Hutwagner L., Clin. Infect. Dis., 21, 897-904 (1995).

5) Edwards J. E., Jr., Bodey G. P., Bowden R. A., Buchner T., de Pauw B. E., Filler S. G., Ghannoum M. A., Glauser M., Herbrecht R., Kauffman C. A., Kohno S., Martino P., Meunier F., Mori T., Pfaller M. A., 
Rex J. H., Rogers T. R., Rubin R. H., Solomkin J., Viscoli C., Walsh T. J., White M., Clin. Infect. Dis., 25, 43-59 (1997).

6) Anttila V. J., Ruutu P., Bondestam S., Jansson S. E., Nordling S., Farkkila M., Sivonen A., Castren M., Ruutu T., Clin. Infect. Dis., 18 979-981 (1994).

7) Fleury F. J., Clin. Microbiol. Rev., 9, 345-348 (1981).

8) Horowitz B. J., Am. J. Obset. Gynecol., 165, 1188-1192 (1991).

9) Gallis H. A., Drew R. H., Pickard W. W., Rev. Infect. Dis., 12, 308 329 (1990).

10) Hartsel S. C., Bolard J. A., Trends Pharmacol. Sci., 12, 445-449 (1996).

11) Matsuoka S., Murata M., Biochim. Biophys. Acta, 1564, 429-434 (2002).

12) Fonos V., Cataldi L., J. Chemother, 12, 463- 470 (2000).

13) Mayer J., Doubek M., Doubek J., Horky D., Scheer P., Stepanek M., J. Infect. Dis., 186, 379-388 (2002).

14) Sugar A. M., Hitchcock C. A., Troke P. F., Picard M., Antimicrob. Agents Chemother, 39, 598-601 (1995).

15) Vazquez J. A., Argonoza M. T., Vaishampayan J. K., Akins R. A., Antimicrob. Agents Chemother, 40, 2511-2516 (1996).

16) Lewis R. E., Lund B. C., Klepser M. E., Ernst E. J., Pfaller M. A., Antimicrob. Agents Chemother, 42, 1382-1386 (1998).

17) Sanglard D., Enferm. Infec. Microbiol. Clin., 20, $462-469$ (2002).

18) Masia Canuto M., Gutierrez Rodero F., Lancet. Infect. Dis., 2, 550-
563 (2002).

19) MacNeill C., Weisz J., Carey J. C., J. Reprod Med., 48, 63 - 68 (2003).

20) Wink M., "The Alkaloids," ed. by Cordell G. E., Academic Press, New York, 1993, pp. 1-118.

21) Schmeller T., Latz-Brunger T., Wink M., Phytochemistry, 44, 257266 (1997).

22) Nakamoto K., Sadamori S., Hamada T., J. Prosthet. Dent., 64, 691694 (1990).

23) Park K. S., Kang K. C., Kim J. H., Adams D. J., Johng T. N., Paik Y. K., J. Antimicrob. Chemoth., 43, 667-674 (1999).

24) Park K. S., Kang K. C., Kim K. Y., Jeong P. Y., Kim J. H., Adams D. J., Kim J. H., Paik Y. K., J. Antimicrob. Chemoth., 47, 513-519 (2001).

25) Hu J. P., Takahashi N., Yamada T., Oral Dis., 6, 297-302 (2000)

26) Severina I. I., Muntyan M. S., Lewis K., Skulacheve V. P., IUBMB Life, 52, 321-324 (2001).

27) Han Y., Dongduk. Pharm. Res., 6, 49-53 (2002).

28) Han Y., Cutler J. E., Infect. Immun., 63, 2714-2719 (1995).

29) Han Y., Ulrich M. A., Cutler J. E., J. Infect. Dis., 179, 1477-1484 (1999).

30) Han Y., Riesselman M. H., Cutler J. E., Infect. Immun., 68, 16491654 (2000).

31) Han Y., Kozel T. R., Zhang M. X., MacGill R. S., Carroll M. C., Cutler J. E., J. Immun., 167, 1550—1557 (2001). 